riously expressed that " a primary atrophy of the gastric mucous membrane occurs, and that in this lesion is to be found an explanation of certain cases of pernicious anxmin."

\title{
A CASE OF SUBCUTANEOUS NODULES IN THE HANDS OF A RHEUMATIC PATIENT.
}

By Geonge S. MImpdetor, M.A., M.D.,

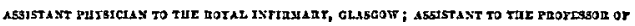
phactice of PHisic, vyitezstry or ansoow.

Mrs. L., aged thirty-nine, presented herself at the outdoor department of the Glasgow Royal Infirmary in November, 1836, complaining of rheumatism, and of painful subcutaneous growths on the fingers of both hands.

She bad an attack of acute rhcumatism when thirteen years of age, and a second in September, 1883. Between these two attacks, and since the last one, she has frequently suffered from rheumatic pains in various joints, such as the knees, ankles, wrists, and finger-joints, accompanied by some swelling of the parts, but not with distinct fever, and not confining her to bed, unless occasionally for a day. There is no cardiac murmur. There is nothing in the history to suggest the existence of a. syphilitic taint.

The swellings on the fingers began during convalescence from the second attack of acute rheumatism, in September, 1883. According to the patient's statement, they were not at first permanent, coming and going; but they have been present more or less, as they are now, since early in 1884, though they are said to vary in size and in hardness.

They began as flattened elevations of the skin, and the most recent ones present something of that appearance now. But the majority are distinctly circumscribed tumors, some the size of a pea, others the size of a small hazelnut. The larger ones are lobulated, being apparently composed of two or more that have coalesced. A few of them feel soft and elastic, but in none is there any indication of fluctuation; the rest are hard, like cartilage, but none have either a chalky or a bony hardness. During the eight months she has been under observation, it cannot be said that they have distinctly varied either in size or bardness, although she herself is of opinion that they have.

The most striking swellings are on the flexor aspects of the fingers. which, as will be seen in the woodeut (from a photagraph by Dr. Miacewen), present something of the appearance of a knotted blackthorn stick. There are between twenty and thirty growths on the fingers of xo. crIIX74., $\rightarrow$ croser, 1857. 
the right hand, and between ten and twenty on the left; it is dificult to Etate the exact number, owing to the fact that so many have coalesced. They are freely movable on the subjacent structures, but the skin is adherent to all but two of these tumors on the fingers. Oper nany of

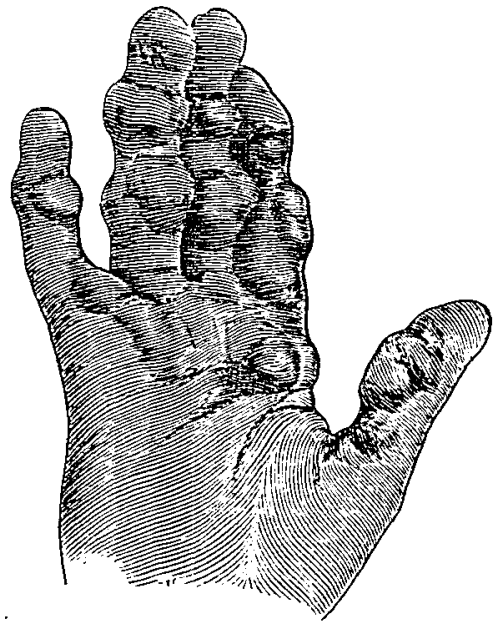

them the skin is thickened, and the superficial layers are rubbed of:. Many of them present a dull, whitish appenrance, intensified by drawing the skin tightly over them. They are itchy, and sore when rubbed. At times they are quite free from pain, but they are very liable to become painful; and the pain in them is most acute when they are growing, during the prevalence of east wind, and just prior to rainy weather. Putting the hands in cold water always causes pain. They have occasionally bled, as after rubbing them, or after a heavy washing of clothes. They have nerer suppurated.

A fer similar swellings are said to have been seen on the toes, but have disappeared. There are none on the scalp, and none on the ears. The only other situation where a swelling of apparently the same characters is met with is at the right elbor. On the right olecranon there is a prominent swelling, which appears to consist of a deep, hard, bony growth, immovable, and quite different from the above, with a mass of softer material like a bursa over it. Distal to this, there is a small, 
movable tumor felt under the skin, to which, however, it is not adherent, and probably of the same nature as the growths above described.

At the knuckles there are smaller swellings, which, however, do not seem to have attracted her attention. They are not like the above, but resemble fusiform enlargements of the sheaths of the tendons, with which alone they move. They are not so circumscribed as those already described, and they have no connection with the skin. They are present on all the knuckles, except those of the little finger and thumb on the right, and of the thumb on the left hand.

There is distinct crepitation felt at the knuckles of the left hand, especially on the flexor aspect, and on the ring finger more than elsewhere. In the sheaths of the flexor tendons, both above and below the anuular ligament at both wrists, there is crepitation on movement, and several bodies are felt moving along with the movement of the tendons, but not capable of being pressed from the distal to the peripheral side of the ligament. They resemble the loose bodies sometimes found in this situation, but are less movable and ferer in number.

Various remedies were tried to relieve the pain, the one that seemed of most use being a combination of bromide of potassium and liquor arsenicalis.

The case was shown at the Pathological and Clinical Society of Glas. govi in December, 1886, when Drs. Macewen and Newman were appointed, along with myself, a committee for its further investigntion. Recently, having obtained the patient's consent, Dr. Macewen removed a mass from the front of the left thumb, and found it to consist of two separate tumors, the one single, the other composed of three that had coalesced. The tumors were adherent to the skin, hard, and distinctly circumscribed, but without any capsule; and in their removal the sheath of the tendon was exposed, but there was no adhesion to it. On section, the tumor was white and glistening, like filrous tissue.

On microscopic examination we found "that where the tumor has approached most closely to the surface, and is most dense, the papille of the skin have become obliterated, and the layer of epithelium attenuated, the stratum corneum being reduced to about one-third of its normal size. In passing from that area, papillo again present themselves, small in size, and zradually increasing on receding from this centre. Where the papilla are lost, the bloodvessels have also in the main disappeared. The growth as a whole is made up of connective tissue in various stages of development. In its substance there are scarcely any bloodressels, but at its periphery the arteries seem to be abnormally numerous, and in many instances their coats are greatly thickened by infiltration with cells, the tuaica intima being frequently particularly affected. In one instnnce, besides accumulation of cells in the intima and in the adventitin, there is a collection of cells dissecting the middle coat, which is 
also greatly thickened. Collections of these cells frequently extead to a considerable distance from the ressels, and in many sections they map out the course of the minute vessels in the papills of the skin. Glandular tissue and fat are almost entirely absent."

As regards its structure, the most striking feature is the condition of the vessele, from which it might be inferred that the lesion has its origin in them, as if from some irritant carried by the blood.

The close relatiouship between the origin of these tumors and an attack of rheumatic fever, and the fact that they are now also most painful when she suffers from rheumatic pains in the joints, lead me to believe that they are of rheumatic origin, a belief strengthened by the absence of anything in her past history to suggest a syphilitic taint.

In connection with this case, my attention has been directed to a paper on "Subcutaneous Nodules connected with Fibrous Structures Occurring in Children the subjects of Rheumatism and Chorea," by Drs. Barlow and Warner, ${ }^{1}$ and to cases shown at the Clinieal Society, London, by Drs. Dyce Duckworth,' Stephen Hackenzie, and Kingston Fowler." The case above recorded differs in many respects in its clinical features from those recorded by them, while in its microscopic characters it closely resembles the tumors they examined, with, however, some points of difference. - I am inclined, therefore, to agree with Dr. Duckworth when he says that " $a$ more extended study of these cases will show that there are eeveral types or varieties of them." Indeed, since ray attention has been directed to the subject, I have been led to believe that subcutaneous aodules on rheumatic hands are more cornmon than one would suppose, from the references made to them in literature, by the fact that $I$ have seen at the Royal Infirmary Dispensary several cases presenting such nodules.

OLWSOF, July, 1837 .

\title{
CIRCULAR SUTURE OF THE INTESTINE-AN EXPERIMENTAL STUDY.s
}

\author{
BY Willias S. HaLsted, M.D., \\ of SEw rous.
}

Arrovg the most brilliant triumphs of modern surgery are those which have attended operations involring laparotomy. We cun offer a scientific explanatiou why may abdominal operntions-above all, ovariotomy - should succeed so well even without the use of antisepties. The

\footnotetext{
1 Tras. Intertat. Mel. Coagress, Lrondoa, 1831, rol. ir. p. 11 a

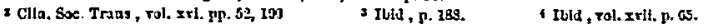

- 3y experiments wero completid Aprh 1, 1S57, anil in a lecturo whith I dellvered at tho Herrard Irodical School, April 5, 1997, I garo ta subatanco that I hare written for this articlo.
} 